\title{
Assessing the role of multiple pregnancies in the association between tetralogy of Fallot and assisted reproductive techniques: a path-analysis approach
}

\author{
Karim Tararbit ${ }^{*}$, Nathalie Lelong ${ }^{1}$, Lucile Houyel ${ }^{2}$, Damien Bonnet ${ }^{3}$, François Goffinet ${ }^{1,4}$, Babak Khoshnood ${ }^{1}$ \\ and On behalf of the EPICARD study group
}

\begin{abstract}
Background: Assisted reproductive techniques (ART) are associated with a higher risk of tetralogy of Fallot (TOF) and multiple pregnancies may be associated with a higher risk of congenital anomalies. We assessed the extent to which the association between ART and risk of TOF may be mediated by the higher risk of multiple pregnancies associated with ART.

Methods: We conducted a case-control study using population-based data from the Paris Registry of Congenital Malformations for the period 1987-2009 and a cohort study of congenital heart defects (EPICARD). The study population included 395 cases of TOF and 4104 malformed controls with no known associations with ART. The analysis was based on a path-analysis model using a counterfactual approach, which allows decomposition of the total effect of ART into an indirect effect (that mediated by the association between ART and multiple pregnancies) and a direct effect.
\end{abstract}

Results: ART (all methods combined) were associated with a 2.6-fold higher odds of TOF after adjustment for maternal and paternal characteristics and year of birth (adjusted OR 2.6, 95\% Cl, 1.5-4.5). Most (79\%) of the effect associated with ART was a direct effect (i.e., not mediated by multiple pregnancies), whereas $21 \%$ of the effect of ART was due to its association with multiple pregnancies (i.e., the indirect effect). In vitro fertilization with intracytoplasmic sperm injection was associated with a 3.5-fold higher odds of TOF (adjusted OR 3.5, 95\% Cl, 1.1-11.2); 11\% of this effect was mediated through the association of ICSI with multiple pregnancies.

Conclusions: By far, most of the higher risk of TOF associated with ART is a direct effect and only a small proportion of the effect may be mediated by multiple pregnancies.

Keywords: Multiple pregnancies, Reproductive techniques, Assisted, Heart defects, Congenital, Tetralogy of Fallot, Epidemiology

\section{Background}

Assisted reproductive techniques (ART) are methods used to achieve pregnancy in case of female and/or male infertility. ART are known to be associated with a higher risk of multiple pregnancies [1,2], mostly due to superovulation or transfer of two or more eggs or embryos. An overall higher

\footnotetext{
* Correspondence: karim.tararbit@inserm.fr

'Inserm, UMR 5953, Epidemiological research on perinatal health, mothers and children health, Port-Royal Maternity, 6ème étage 53 avenue de l'Observatoire, Paris 75014, France

Full list of author information is available at the end of the article
}

risk of congenital malformations in fetuses conceived following ART has been reported in several studies [3-10] using different study populations and designs and methods of analysis and at times inconsistent results, particularly for specific anomalies [6].

Few studies have assessed specifically the risk of congenital heart defects (CHD) associated with ART [6,11-15]. These studies have found an increased risk of $30-50 \%$ (Odds ratios $~ 1.3-1.5$ ) of the overall risk of CHD, which varied across categories of CHD and methods of ART [12-15]. In particular, a recent study assessing the

\section{Ciomed Central}

(c) 2014 Tararbit et al.; licensee BioMed Central Ltd. This is an Open Access article distributed under the terms of the Creative Commons Attribution License (http://creativecommons.org/licenses/by/2.0), which permits unrestricted use, distribution, and reproduction in any medium, provided the original work is properly credited. The Creative Commons Public Domain Dedication waiver (http://creativecommons.org/publicdomain/zero/1.0/) applies to the data made available in this article, unless otherwise stated. 
risk for four individual CHD, (Transposition of Great Arteries, Hypoplastic Left Heart, Coarctation of Aorta and Tetralogy of Fallot (TOF)) [15] found a specifically higher risk of TOF associated with ART. In contrast, the authors found no statistically significant associations with the other three defects examined and the effect sizes (odds ratios) were close to the null value (i.e., close to one).

Even if multiple pregnancies may be independently associated with a higher risk of congenital anomalies [16,17] and this may be specifically the case for CHD, relatively little information exist on the specific association between multiple pregnancies and CHD [18-20], particularly for individual defects [21].

Given: i) the previous finding of the specific association between ART and TOF [15], ii) the known association between ART and multiple pregnancies, and iii) the possible association of the latter with the risk of congenital anomalies, the objective of the present study was to assess the impact of multiple pregnancies in the association between TOF and ART using a path-analysis model.

\section{Material and methods Data sources}

Two sources of data were used for this study: 1) the Paris Registry of Congenital Malformations and 2) the EPICARD study (Epidemiological study on the outcomes for congenital heart diseases). These two sources of data are briefly described below.

\section{The Paris Registry of Congenital Malformations}

Since 1981, the Paris Registry of Congenital Malformations registers all cases of birth defects and chromosomal anomalies among live-births, still-births ( $\geq 22$ weeks of gestation) and termination of pregnancy for fetal anomaly. The Registry covers the population of women who live in Greater Paris area (Paris and its surrounding suburb) and deliver or have a termination of pregnancy for fetal anomaly in a Parisian maternity unit. The annual number of deliveries in our population is about 38,000.

The Paris Registry is a member of the European network of registries of congenital malformations (EUROCAT) and of the International clearinghouse for birth defects surveillance and research [22-25]. The Registry follows the EUROCAT methodology and quality of data is routinely monitored by both EUROCAT and the National committee of registries in France. Review of procedures regarding confidentiality of data is overseen by both the National committee of registries and the National committee of informatics and freedom. Data are based on medical records and are collected from several sources including maternity units, neonatology wards, cytogenetic and pathology services.

In the present study, data from the Registry corresponded to the period 1987 to 2009 as the first case of a malformation with exposure to IVF occurred in 1987 and 2009 was the last year for which data were available at the time of the study.

\section{EPICARD}

The EPICARD study [26] is an ongoing prospective cohort study of all children with a CHD born to women living in the Greater Paris area (Paris and its surrounding suburbs) between 2005 and 2008 regardless of place of delivery (total number of births 317538). The principal objectives of the study are to use population-based data from a large cohort of patients with CHD to: i) estimate total and live birth prevalence, pre- and postnatal diagnosis of CHD; ii) assess medical and surgical management of children with $\mathrm{CHD}$, iii) evaluate neonatal mortality and morbidity and neuro-developmental outcomes of children with CHD; and iv) identify the factors associated with their health outcomes, especially the role of events during the neonatal period and of the initial medical and surgical management. All cases (live births, terminations of pregnancy for fetal anomaly, fetal deaths) diagnosed in the prenatal period or up to one year of age in the birth cohorts between May 1st 2005 and April 30th 2008 were eligible for inclusion. The total number of cases included in the study was 2867, including 2348 newborns (82\%), 466 terminations of pregnancy for fetal anomaly (16.2\%) and 53 fetal deaths (1.8\%). Diagnoses were confirmed in specialized paediatric cardiology departments and for the majority of terminations of pregnancy for fetal anomaly and fetal deaths by fetopathologist examination; for others in which a pathology exam could not be done (26\%) the diagnoses were confirmed by consensus by a paediatric cardiologist and a specialist in echocardiography based on results of prenatal echocardiography examination.

\section{Methods}

We conducted a case-control study with malformed controls. Cases were fetuses/newborns with tetralogy of Fallot (TOF). Two sources of data, the EPICARD study and the Paris Registry of Congenital Malformations (1987-2009), were used for inclusion of cases. The data source for the malformed controls was the Paris Registry data (19872009 , i.e., the same period as for the cases). Malformed controls were isolated cases of single malformations (i.e. those that were not associated with chromosomal or any other anomalies / genetic syndromes) and for which no evidence of an association with ART was found in the literature. As recommended by Hook [27], we selected a wide spectrum of heterogeneous birth defects as controls in order to decrease the risk of selection bias due to shared etiologic factors between cases and controls. The malformations in the control group comprised club-foot, angioma, skin abnormalities, polydactyly, syndactyly and congenital hip dislocation. 
Exposure to ART included the following categories: inductors of ovulation only (IO), in vitro fertilization (IVF) only and IVF with intracytoplasmic sperm injection (IVF + ICSI). Exposure to ART was assessed as: i) a binary variable (ART yes/no), ii) a variable in four categories (no ART, IO, IVF only, IVF + ICSI) and iii) a variable combining IVF only and IVF with ICSI (IVF +/- ICSI) in a single category.

Potential confounding factors considered were maternal characteristics (age, occupation and geographic origin), paternal age and year of birth (or termination of pregnancy for fetal anomaly). Although their exact relations to the risk for specific CHD are not well known, these factors are associated with both exposure to ART and prevalence of birth defects in general [28,29]. Maternal occupation was coded in five categories (professional, intermediate, administrative/public service, other and none) following the French National Institute of Statistics and Economic Studies (INSEE) classification. Geographic origin was coded in four categories: French, North African, SubSaharan African and other countries.

\section{Statistical analysis}

We conducted a logistic regression analysis using a pathanalysis model $[30,31]$ to decompose the total effect associated with ART into an indirect effect (that mediated by the association between ART and multiple pregnancies) and a direct effect (Figure 1). The path-analysis model uses a counterfactual ("what if") approach and its basis may be formulated conceptually as the response to the following question: "What would be the risk of TOF associated with ART if ART-conceived fetuses had the same probability of multiple pregnancies as spontaneously-conceived fetuses?"

In case of a binary exposure, two estimates of the direct and indirect effects are possible. The first one is based on the answer to the counterfactual question above. The second estimate is based on the alternative question: "What would be the risk of TOF associated with ART if spontaneously-conceived fetuses had the same probability of multiple pregnancies as ART-conceived fetuses?" These two estimates are not necessarily the same, although they are usually very similar. One suggestion is to report the average of these two estimates for assessing the direct vs.

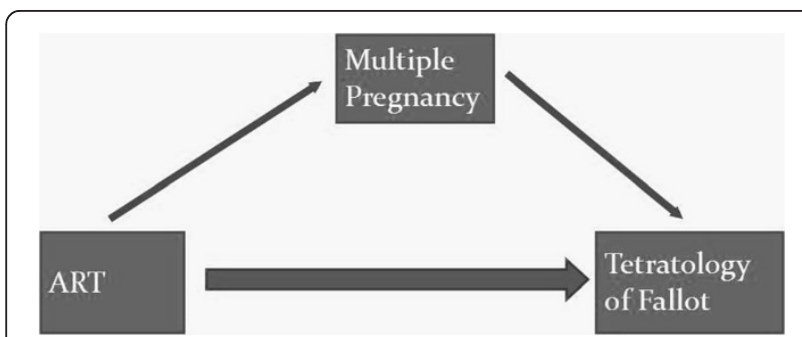

Figure 1 Decomposition of the total effect of ART on the risk of TOF into a direct effect and an indirect effect mediated through multiple pregnancies. indirect (mediated) effect of the exposure. In our study the two set of estimates were very similar and we reported the estimates that corresponded to the first counterfactual question noted above.

Analyses were conducted for all cases of TOF and for "isolated" cases of TOF (i.e. excluding cases associated with chromosomal anomalies or anomalies of other systems).

The statistical significance level was set at $\alpha=0.05$ and all tests were two-sided. Analyses were done with Stata 11 software (Statacorp, Texas, USA) and add-on models developed by Buis [30].

\section{Ethics}

No specific ethical approval was needed for this particular analysis. The French National Committee of Informatics and Freedom (CNIL) has authorised the surveillance and research activities of the Registry using anonymous data and has approved the EPICARD study.

\section{Results}

\section{Study population}

The study population included 404 cases of TOF, among which 97.8\% $(\mathrm{n}=395)$ had complete data on ART. Associated chromosomal anomalies were found in $20.3 \%(n=80)$ of the cases of TOF. The control group included $4250 \mathrm{fe}-$ tuses, among whom $96.6 \%(n=4104)$ fetuses had complete data on ART. The control group included $35.0 \%(\mathrm{n}=1$ 436) with congenital hip dislocation, $20.0 \%(n=824)$ with club-foot, $19.1 \%(\mathrm{n}=782)$ with polydactyly, $12.6 \%(\mathrm{n}=517)$ with angioma, $9.3 \%(\mathrm{n}=38)$ with skin abnormality, and $4.0 \%(\mathrm{n}=164)$ with syndactyly.

Table 1 shows the comparison of the characteristics of cases of TOF and controls. Cases and controls were different for most characteristics. In particular, mothers of cases of TOF were older than mothers of controls (31.7 vs. 30.4 years, $\mathrm{p}<0.001)$, and were more likely to be from North Africa (18.1 vs. $10.4 \%, \mathrm{p}<0.001)$. Stillbirths and terminations of pregnancy for fetal anomaly were more likely to occur for cases of TOF than controls ( 4.5 vs. $0.2 \%$ and $29.0 \%$ vs. $0.3 \%$ respectively, $\mathrm{p}<0.001$ ). Cases of TOF were more likely to have been conceived following ART (all methods combined) than controls (6.6 vs. $3.5 \%, \mathrm{p}=0.002)$. Exposure to the different methods of ART also differed significantly between cases and controls. In particular, $1.3 \%$ of cases of TOF were conceived following IVF + ICSI vs. $0.3 \%$ of controls $(\mathrm{p}<0.001)$. The study population included 329 cases of TOF and 2670 controls conceived spontaneously. The odds of TOF was 1.5-fold higher $(\mathrm{OR}=1.5,95 \% \mathrm{CI} 0.8-2.7)$ in twins vs. singleton pregnancies conceived spontaneously; however, this association was not statistically significant $(\mathrm{p}=0.17)$.

Table 2 shows the comparison of the study population characteristics according to exposure to ART (all methods combined). Mothers who had conceived following ART 
Table 1 Associations between predictor variables and case/control status

\begin{tabular}{|c|c|c|c|c|c|c|}
\hline \multirow[t]{2}{*}{ Characteristics } & & \multicolumn{2}{|c|}{ TOF $(\mathrm{N}=404)$} & \multicolumn{2}{|c|}{ Controls ( $\mathrm{N}=4250)$} & \multirow[t]{2}{*}{$p$} \\
\hline & & $\mathrm{n}^{*}$ & $\%^{\S}$ & $\mathrm{n}^{*}$ & $\%^{\S}$ & \\
\hline \multirow[t]{19}{*}{ Mother } & Age (years) & & & & & \\
\hline & Mean (SD) & \multicolumn{2}{|c|}{$31.7(5.6)$} & \multicolumn{2}{|c|}{$30.4(5.2)$} & $<0.001$ \\
\hline & Median (p25-p75) & \multicolumn{2}{|c|}{$31.5(28-36)$} & \multicolumn{2}{|c|}{$30(27-34)$} & \\
\hline & $<20$ & 3 & 0.8 & 59 & 1.4 & $<0.001$ \\
\hline & $20-29$ & 146 & 36.5 & 1,809 & 42.8 & \\
\hline & $30-34$ & 126 & 31.5 & 1,434 & 33.9 & \\
\hline & $35-39$ & 91 & 22.8 & 722 & 17.1 & \\
\hline & $\geq 40$ & 34 & 8.5 & 203 & 4.8 & \\
\hline & Geographic origin & & & & & \\
\hline & France & 200 & 50.4 & 2,412 & 57.9 & $<0.001$ \\
\hline & North Africa & 72 & 18.1 & 433 & 10.4 & \\
\hline & Subsaharan Africa & 39 & 9.8 & 550 & 13.2 & \\
\hline & Other & 86 & 21.7 & 770 & 18.5 & \\
\hline & Occupation & & & & & \\
\hline & None & 113 & 30.9 & 1,083 & 26.3 & 0.096 \\
\hline & Professional & 84 & 23.0 & 997 & 24.2 & \\
\hline & Intermediate & 64 & 17.5 & 856 & 20.8 & \\
\hline & Administrative/public service & 67 & 18.3 & 852 & 20.7 & \\
\hline & Other & 38 & 10.4 & 330 & 8.0 & \\
\hline \multirow[t]{19}{*}{ Father } & Age (years) & & & & & \\
\hline & Mean (SD) & \multicolumn{2}{|c|}{$35.0(6.6)$} & \multicolumn{2}{|c|}{$33.9(6.6)$} & 0.006 \\
\hline & Median (p25-p75) & \multicolumn{2}{|c|}{$34(30-39)$} & \multicolumn{2}{|c|}{$33(29-38)$} & \\
\hline & $<20$ & 1 & 0.3 & 5 & 0.1 & 0.014 \\
\hline & $20-29$ & 59 & 19.5 & 890 & 25.8 & \\
\hline & $30-34$ & 94 & 31.1 & 1,198 & 34.7 & \\
\hline & $35-39$ & 79 & 26.2 & 734 & 21.3 & \\
\hline & $\geq 40$ & 69 & 22.9 & 734 & 21.3 & \\
\hline & Geographic origin & & & & & \\
\hline & France & 179 & 49.2 & 2,325 & 58.6 & $<0.001$ \\
\hline & North Africa & 66 & 18.1 & 416 & 10.5 & \\
\hline & Subsaharan Africa & 38 & 10.4 & 529 & 13.3 & \\
\hline & Other & 81 & 22.3 & 700 & 17.6 & \\
\hline & Occupation & & & & & \\
\hline & None & 24 & 7.6 & 281 & 7.4 & 0.014 \\
\hline & Professional & 110 & 34.6 & 1,474 & 38.6 & \\
\hline & Intermediate & 44 & 13.8 & 566 & 14.8 & \\
\hline & Administrative/public service & 28 & 8.8 & 479 & 12.5 & \\
\hline & Other & 112 & 35.2 & 1,020 & 26.7 & \\
\hline \multirow[t]{4}{*}{ Pregnancy } & Outcome & & & & & \\
\hline & Still-births & 18 & 4.5 & 7 & 0.2 & $<0.001$ \\
\hline & Live-births & 269 & 66.6 & 4,231 & 99.6 & \\
\hline & Pregnancy terminations & 117 & 29.0 & 12 & 0.3 & \\
\hline Art & None & 369 & 93.4 & 3,959 & 96.5 & 0.004 \\
\hline
\end{tabular}


Table 1 Associations between predictor variables and case/control status (Continued)

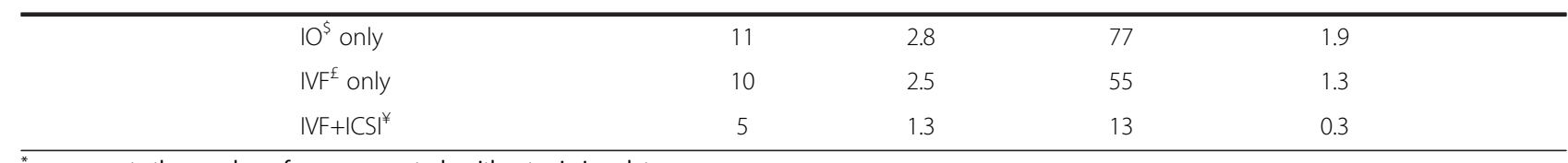

*n represents the number of cases or controls without missing data.

$\varsigma_{\%} \%$ calculated with the number of cases or controls without missing data as a denominator.

\$nductors of ovulation.

${ }^{\mathrm{E}}$ In vitro fertilization.

${ }^{¥}$ IVF with intracytoplasmic sperm injection.

were older than mothers who had conceived spontaneously (33.0 vs. 30.4 years, $\mathrm{p}<0.001$ ), more likely to be of French origin ( 72.9 vs. $56.4 \%, \mathrm{p}<0.001)$ and in the highest occupational category "professional" (35.5 vs. $23.6 \%, \mathrm{p}<0.001)$. Multiple births were more likely to occur after ART conception ( 23.7 vs. $2.9 \%$ for twins and 4.6 vs. $0.1 \%$ for triplets, $\mathrm{p}<0.001)$. Still-births also tended to be more likely in the ART conceived fetuses (1.8 vs. $0.5 \%, \mathrm{p}=0.099$ ).

\section{Risk of TOF associated with ART: direct and indirect (mediated by multiple pregnancies) effects All cases of TOF}

Table 3 summarizes the results of logistic regression analyses of the association between TOF and ART, including the path-analysis estimates for the decomposition of the total effect of ART into its direct and indirect (mediated by multiple pregnancies) components.

ART (all methods combined) were associated with a significant increase in the odds of TOF (total effect: adjusted OR 2.6, 95\% CI 1.5 - 4.5). The ART conceived fetuses would have had a 2.1-higher odds of TOF than spontaneously conceived fetuses if the risk of multiple pregnancies were kept constant at the level of spontaneously conceived fetuses (direct effect: adjusted OR 2.1, $95 \%$ CI 1.2 - 3.7). This estimates suggested in turn that about $21 \%$ of the overall higher odds of TOF associated with ART was due to the higher probability of multiple pregnancies following ART.

IO were associated with a 2.1-higher odds of TOF (total effect: adjusted OR 2.1, 95\% CI 1.0 - 4.7). The IO conceived fetuses would have had a 1.8-higher odds of TOF than spontaneously conceived fetuses if they had the same risk of multiple pregnancies as for spontaneously conceived fetuses (direct effect: adjusted OR 1.8, 95\% CI 0.9 - 3.9). Hence, about $19 \%$ of the overall higher odds of TOF associated with IO was due to the higher probability of multiple pregnancies following IO.

IVF only was associated with a 2.8-higher odds of TOF (total effect: adjusted OR 2.8, 95\% CI 1.2 - 6.7). Approximately $28 \%$ of this overall higher odds of TOF associated with IVF only was due to the higher probability of multiple pregnancies following IVF only.

Finally, IVF + ICSI was associated with a 3.5-higher odds of TOF (total effect: adjusted OR 3.5, 95\% CI 1.1 - 11.2).
The IVF + ICSI conceived fetuses would have had a 3.1higher odds of TOF than spontaneously conceived fetuses if they had the same risk of multiple pregnancies as for spontaneously conceived fetuses (direct effect: adjusted OR $3.1,95 \%$ CI 0.9 - 10.1). Therefore, about $11 \%$ of the overall higher odds of TOF associated with IVF + ICSI was due to the higher probability of multiple pregnancies following IVF + ICSI.

\section{Isolated cases of TOF}

Table 4 summarizes the results of logistic regression analyses of the association between isolated cases of TOF (excluding cases associated with chromosomal or other anomalies), including the path-analysis estimates for the decomposition of the total effect of ART into its direct and indirect (mediated by multiple pregnancies) components..

The estimates were essentially similar to those found for all cases combined (i.e. when cases of TOF with and without associated anomalies were analysed together).

\section{Discussion}

Using population-based data on approximately 400 cases of tetralogy of Fallot (TOF) and 4000 malformed controls, we assessed the previously reported higher risk of TOF [15] that may be due (mediated by) multiple pregnancies in fetuses conceived following assisted reproductive technologies (ART). We used a path-analysis model based on a counterfactual approach in order to decompose the total effect associated with ART into a direct and an indirect effect (i.e. that due to the association between ART and multiple pregnancies).

Our results showed that of the overall 2.6-fold higher odds of TOF in fetuses conceived following ART, 20\% was due to the higher likelihood of multiple pregnancies in fetuses conceived following ART (the "indirect effect"). This suggests in turn that multiple pregnancies themselves may be associated with a higher risk of TOF, albeit much less so than ART. The contribution of multiple pregnancies to the higher odds of TOF associated with ART (i.e. the indirect effect) varied according to the method of ART. Our estimates suggested that $30 \%$ of the total effect of IVF only was due to multiple pregnancies vs. $11 \%$ in the case of IVF + ICSI. The results were similar for analyses restricted 
Table 2 Comparison of the study population characteristics according to exposure to ART (all methods combined) Variable

\begin{tabular}{cc} 
& \\
& No \\
\hline $\mathbf{n}$ & \\
& \\
& \\
& $30.4(5.2)$ \\
& $(27-34)$
\end{tabular}

Exposure to ART

$\geq 40$

Geographic origin

France

North Africa

Subsaharan Africa

Other

Occupation

None

Professional

Intermediate

Administrative/public service

Other

Father

\begin{tabular}{|c|c|}
\hline & Mean (SD) \\
\hline & Median (p25-p75) \\
\hline & $<20$ \\
\hline & $20-29$ \\
\hline & $30-34$ \\
\hline & $35-39$ \\
\hline & $\geq 40$ \\
\hline & Geographic origin \\
\hline & France \\
\hline & North Africa \\
\hline & Subsaharan Africa \\
\hline & Other \\
\hline & Occupation \\
\hline & None \\
\hline & Professional \\
\hline & Intermediate \\
\hline & Administrative/public service \\
\hline & Other \\
\hline Pregnancy & Outcome \\
\hline & Still-births \\
\hline & Live-births \\
\hline & Pregnancy terminations \\
\hline
\end{tabular}

61

1,874

1,440

727

213

Yes

$\%^{\S} \quad n$

Yes

$\%^{\S}$

$33.0(4.6)$
$33(30-37)$

$<0.001$

$<0.001$

$39 \quad 22.8$

$68 \quad 39.8$

$52 \quad 30.4$

$12 \quad 7.0$

2,416

484

56.4

72.9

6.5

573

11.3

11

5.3

808

13.4

18.9

15.3

1,134

27.1

14.2

$<0.001$

988

23.6

35.5

851

20.3

25.4

867

20.7

16.6

346

8.3

8.3

33.9 (6.6)

$35.0(5.8)$

0.044

$33(29-38)$

$34(31-38)$

0

0.0

$<0.001$

924

0.2

17

10.8

42.0

1,206

26.1

66

29.9

756

21.3

47

17.2

652

27.0

27

2,327

57.1

71.5

0.002

463

11.4

6.7

6.7

550

13.5

18.1

15.2

291

7.5

3.7

0.023

1,454

37.7

49.1

573

14.9

15.3

480

1,060

12.4

27.5

8.6

23.3

\section{.}


Table 2 Comparison of the study population characteristics according to exposure to ART (all methods combined) (Continued)

\begin{tabular}{lccccc} 
Multiplicity & & & & & \\
Singletons & 2,908 & 97.0 & 94 & 71.8 & $<0.001$ \\
Twins & 88 & 2.9 & 31 & 23.7 & \\
Triplets & 3 & 0.1 & 6 & 4.6 & \\
\hline
\end{tabular}

${ }_{5} \%$ calculated with the total of cases or controls without missing data as a denominator.

to isolated cases of TOF (excluding those associated with chromosomal or other anomalies).

In order to estimate the risk of congenital malformations in multiple pregnancies conceived following ART, previous studies have generally included separate (stratified) analyses for singletons and multiple pregnancies $[8,9,12,13,15,32]$. This approach can be informative in examining the association between ART and the risk of congenital malformations, in particular regarding the possible existence of an interaction effect between ART and multiple pregnancies. However, these studies did not formally test for statistical significance of any such interaction and had limited power to detect them if they indeed existed. In any case, this approach does not allow a formal estimation of the proportion of the effect of ART on the risk of congenital malformations that may be due to multiple pregnancies.

We found that the "direct" effect associated with ART (i. e. that not mediated by multiple pregnancies) was substantially greater than the indirect effect. This was particularly so in the case of IVF + ICSI. This finding may provide clues as to the underlying mechanisms of the association between ART, particularly for IVF + ICSI, and TOF. The developmental basis of TOF is complex, incompletely elucidated and probably multifactorial $[33,34]$. The implication of genomic imprinting [35-38] and a role for cardiac neural crest cells in the development of TOF have been suggested [34,39] but any implication of ART in these pathways remains to be shown.

Regarding any effects (the indirect effect) due to twinning, our study was not designed to elucidate what may be the underlying mechanism of any association between twinning and risk of TOF (independently of exposure to ART). In particular, we did not take into account zygosity (or chorionicity), whereas the risk of congenital anomalies in monozygotic twins appears to be higher than that of dizygotic twins $[16,17,20]$. Our results suggest however, that any effects due to twinning per se, whatever its underlying mechanism may be, are likely to be small. Hence, it is possible that twin pregnancies, even in the case of monozygotic twins, are not (or only to a small extent are) associated with a higher risk of TOF, whereas for other CHD twinning per se may be a more important risk factor $[16,17,20]$.

We also did not account for any potential effect of the "vanishing" twin syndrome on our estimates. Several studies have found that ART multiple pregnancies in which a twin vanished had poorer obstetrical and perinatal outcomes [40-43]. However, to our knowledge, there is no documented association between the vanishing twin syndrome and risk of birth defects in general or of CHD in particular. If indeed such an association exists in the case of TOF, misclassification of vanishing twin pregnancies as singletons would result in an underestimation of the mediating effect of multiple pregnancies in the association between ART and risk of TOF.

Our study has certain limitations. Even if the total number of cases of TOF and controls was fairly large, the numbers of cases exposed to the different methods of ART were small and hence confidence interval were fairly wide reflecting the relative imprecision of our estimates of ORs particularly for specific techniques of ART.

Although we chose frequent and heterogeneous malformations for which no association with ART exist in the literature, bias due to the association between ART and malformations in the control group cannot be excluded. In particular, if ART were associated with a higher risk of one or more of the malformations in the control group, the consequence would be an underestimation of the true association between ART and TOF.

Due to a lack of available information in our data, we did not adjust for certain maternal conditions including pregestational or gestational diabetes and obesity, tobacco, alcohol and drug consumption. Although these factors may be associated with risk of birth defects in general, or of CHD in particular, their associations, if any, with the risk of specific CHD, including TOF are generally not known.

We also could not adjust for maternal folic acid/multivitamins use that is associated with a lower risk of CHD [44] and in addition is more frequent in women who conceive following ART [13,45]. Hence, we cannot rule out residual confounding due to risk (or protective) factors associated with ART and/or twinning that were not taken into account.

In addition, our study was not designed to and cannot disentangle the effects that may be due to infertility of couples vs. ART or twinning per se $[4,9,46]$. Some authors have found that the risk of birth defects is increased in infertile women who conceive spontaneously, which suggests that the underlying infertility problems may explain part or perhaps all of the association between ART and 
Table 3 Decomposition of the total effect of ART on the odds of TOF into a direct effect and indirect effect mediated through multiple pregnancies

\begin{tabular}{|c|c|c|c|c|c|c|c|c|c|c|c|c|c|}
\hline \multirow[t]{2}{*}{ Art } & \multicolumn{4}{|c|}{ Total effect } & \multicolumn{4}{|c|}{ Direct effect } & \multicolumn{4}{|c|}{ Indirect effect } & \multirow{2}{*}{$\begin{array}{l}\text { Estimated size o } \\
\text { the indirect effe }\end{array}$} \\
\hline & Unadjusted $\mathrm{OR}^{*}$ & $95 \% \mathrm{Cl}$ & Adjusted§ OR* & $95 \% \mathrm{Cl}$ & Unadjusted $\mathrm{OR}^{*}$ & $95 \% \mathrm{Cl}$ & Adjusted OR* & $95 \% \mathrm{Cl}$ & Unadjusted $\mathrm{OR}^{*}$ & $95 \% \mathrm{Cl}$ & Adjusted OR* & $95 \% \mathrm{Cl}$ & \\
\hline None & 1.0 & ref. & 1.0 & ref. & 1.0 & ref. & 1.0 & ref. & 1.0 & ref. & 1.0 & ref. & \\
\hline $\begin{array}{l}\text { All methods } \\
\text { combined }\end{array}$ & 1.9 & $1.2-3.1$ & 2.6 & $1.5-4.5$ & 1.7 & $1.0-2.8$ & 2.1 & $1.2-3.7$ & 1.1 & $1.0-1.4$ & 1.2 & $1.0-1.5$ & $20.9 \%$ \\
\hline $10^{\$}$ only & 1.4 & $0.7-2.9$ & 2.1 & $1.0-4.7$ & 1.3 & $0.7-2.6$ & 1.8 & $0.9-3.9$ & 1.1 & $1.0-1.2$ & 1.2 & $1.0-1.3$ & $19.1 \%$ \\
\hline IVF ${ }^{£}$ only & 2.2 & $1.0-4.7$ & 2.8 & $1.2-6.7$ & 1.8 & $0.8-3.8$ & 2.1 & $0.9-5.2$ & 1.2 & $0.9-1.6$ & 1.3 & $1.1-1.7$ & $27.8 \%$ \\
\hline$\left.|V F+| C S\right|^{*}$ & 3.1 & $1.0-10.0$ & 3.5 & $1.1-11.2$ & 2.8 & $0.9-8.9$ & 3.1 & $0.9-10.1$ & 1.1 & $1.0-1.3$ & 1.1 & $0.9-1.4$ & $11.1 \%$ \\
\hline$|V F+/-| C S \mid$ & 2.4 & $1.3-4.6$ & 3.0 & $1.6-5.8$ & 2.1 & $1.0-4.3$ & 2.4 & $1.2-4.6$ & 1.2 & $0.9-1.5$ & 1.3 & $1.0-1.6$ & $22.3 \%$ \\
\hline
\end{tabular}

*Odds ratios (OR) represent the odds of a birth (including live births, stillbirths and pregnancy terminations) with TOF (cases) relative to the odds of a birth with one of the malformed controls (club-foot, angioma, skin abnormality, polydactyly, syndactyly, and congenital hip dislocation).

${ }_{5}^{5}$ Adjustment was made for maternal age, occupation, geographic origin, paternal age and year of birth

sInductors of ovulation.

In vitro fertilization.

${ }^{*}$ IVF with intracytoplasmic sperm injection. 
Table 4 Decomposition of the total effect of ART on the odds of TOF without associated chromosomal anomalies into a direct effect and indirect effect mediated through multiple pregnancies

\begin{tabular}{|c|c|c|c|c|c|c|c|c|c|c|c|c|c|}
\hline \multirow[t]{2}{*}{ Art } & \multicolumn{4}{|c|}{ Total effect } & \multicolumn{4}{|c|}{ Direct effect } & \multicolumn{4}{|c|}{ Indirect effect } & \multirow{2}{*}{$\begin{array}{l}\text { Estimated size } \\
\text { the indirect eff }\end{array}$} \\
\hline & Unadjusted $\mathrm{OR}^{*}$ & $95 \% \mathrm{Cl}$ & Adjusted§ OR* & $95 \% \mathrm{Cl}$ & Unadjusted $\mathrm{OR}^{*}$ & $95 \% \mathrm{Cl}$ & Adjusted OR* & $95 \% \mathrm{Cl}$ & Unadjusted $\mathrm{OR}^{*}$ & $95 \% \mathrm{Cl}$ & Adjusted $\mathrm{OR}^{*}$ & $95 \% \mathrm{Cl}$ & \\
\hline None & 1.0 & ref. & 1.0 & ref. & 1.0 & ref. & 1.0 & ref. & 1.0 & ref. & 1.0 & ref. & \\
\hline $\begin{array}{l}\text { All methods } \\
\text { combined }\end{array}$ & 2.3 & $1.5-3.5$ & 3.2 & $2.1-4.7$ & 1.9 & $1.2-3.0$ & 2.5 & $1.6-3.8$ & 1.2 & $1.0-1.4$ & 1.3 & $1.1-1.5$ & $21.5 \%$ \\
\hline $10^{\$}$ only & 1.7 & $0.9-3.1$ & 2.6 & $1.3-5.0$ & 1.5 & $0.8-2.7$ & 2.2 & $1.2-4.0$ & 1.1 & $1.0-1.3$ & 1.2 & $1.0-1.4$ & $18.9 \%$ \\
\hline IVF ${ }^{£}$ only & 2.5 & $1.1-6.1$ & 3.4 & $1.6-7.2$ & 1.9 & $0.8-5.0$ & 2.4 & $1.2-4.8$ & 1.3 & $1.0-1.7$ & 1.4 & $1.0-2.0$ & $29.7 \%$ \\
\hline$\left.|\mathrm{VF}+| \mathrm{CS}\right|^{*}$ & 4.0 & $1.2-13.1$ & 4.4 & $1.2-15.9$ & 3.5 & $1.1-11.5$ & 3.7 & $1.0-13.8$ & 1.1 & $0.9-1.4$ & 1.2 & $0.9-1.5$ & $11.7 \%$ \\
\hline$|\mathrm{VF}+/-| \mathrm{CS} \mid$ & 2.9 & $1.6-5.4$ & 3.7 & $2.0-7.0$ & 2.3 & $1.2-4.6$ & 2.7 & $1.5-4.9$ & 1.2 & $1.0-1.5$ & 1.4 & $1.0-1.9$ & $23.6 \%$ \\
\hline
\end{tabular}

*Odds ratios (OR) represent the odds of a birth (including live births. stillbirths and pregnancy terminations) with TOF (cases) relative to the odds of a birth with one of the malformed controls (club-foot, angioma, skin abnormality, polydactyly, syndactyly, and congenital hip dislocation).

${ }_{5}^{\varsigma}$ Adjustment was made for maternal age, occupation, geographic origin, paternal age and year of birth.

$\$$ Inductors of ovulation.

In vitro fertilization.

*IVF with intracytoplasmic sperm injection. 
risk of birth defects. However, the strategy of "adjusting for infertility" (time to pregnancy or duration of infertility) has been criticized [5] as it could be "synonymous" with exposure to ART. In any case, in our data, essentially all women who had a duration of infertility of more than two years had conceived following ART; adjustment for infertility duration was therefore not feasible in our study.

The frequency of missing data was low for exposure to ART and maternal characteristics. However, paternal age was missing for $25 \%$ of the study population. We adjusted for paternal age as it can be related to ART exposure and particularly ICSI. Results were nevertheless similar when models did not include paternal age and in analyses that included multiple imputation for paternal age (results not shown, available from authors).

\section{Conclusion}

In conclusion, we found that most of the higher risk of TOF associated with ART is a "direct" effect (i.e. not mediated by multiple pregnancies) and only a small proportion of the effect may be due to multiple pregnancies. This was particularly the case for IVF + ICSI and may provide clues about the possible underlying mechanism(s) for the association between ART and TOF. The path-analysis approach presented here may be more generally useful for assessing the role of multiple pregnancies in the association between ART and risk of other congenital malformations or other adverse outcomes.

\section{Competing interests}

The authors declare that they have no competing interest.

\section{Authors' contributions}

BK conceived the study. KT conducted the main statistical analyses and wrote the first draft of the manuscript with BK. NL assisted with statistical analysis. LH, DB and FG contributed to the conceptualization of ideas and made suggestions about the required analyses. $\mathrm{LH}$ and DB provided expertise as pediatric cardiologists. All of the authors contributed to the interpretation of findings and revisions of the article. All authors read and approved the final manuscript.

\section{Acknowledgements}

Inserm Unit 953 has received a grant from the Bettencourt Foundation (Coups d'élan pour la Recherche française) in support of its research activities.

\section{Funding}

This work was supported by grants from the Agence de Biomédecine (Saint-Denis La Plaine, France) (to B.K.). The Paris Registry of Congenital Malformations received financial support from INSERM (Paris, France) and the Institut de Veille Sanitaire (Saint-Maurice, France). The EPICARD study was supported by three grants from the Ministry of Health (PHRC 2004, 2008 and 2011). Additional funding for the EPICARD study was provided by the AREMCAR Association (Association pour la Recherche et l'Etude des Maladies Cardiovasculaires).

\section{EPICARD study group}

Principal Investigators: François Goffinet, Babak Khoshnood Steering Committee: Damien Bonnet (Hôpital Necker Enfants Malades, AP-HP, Centre de référence M3C, Université Paris Descartes, Paris) Johanna Calderon (INSERM U953)

Drina Candilis (Université Paris-Diderot, Paris)
Anne-Lise Delezoide (Hôpital Robert Debré, AP-HP, Service de biologie du Développement, Université Paris-Diderot, Paris)

Catherine De Vigan (INSERM U953, Paris)

François Goffinet (Groupe Hospitalier Cochin-Hôtel Dieu, AP-HP, Maternité Port-Royal et INSERM U953, Université Paris Descartes, Paris)

Lucile Houyel (Hôpital Marie Lannelongue, Service de chirurgie des cardiopathies congénitales, Le Plessis-Robinson)

Jean-Marie Jouannic (Hôpital Trousseau, AP-HP, Centre pluridisciplinaire de diagnosticprénatal, UPMC, Paris)

Babak Khoshnood (INSERM U953, Paris)

Nathalie Lelong (INSERM U953, Paris)

Suzel Magnier (Hôpital Robert Debré, AP-HP, Service de cardiologie, Paris) Jean-François Magny (Institut de Puériculture et de périnatologie, Service de néonatologie, Paris)

Caroline Rambaud (Hôpital Raymond Poincarré, AP-HP, Service d'anatomie et cytologie pathologiques - Médecine légale, UVSQ, Garches)

Dominique Salomon (INSERM U953, Paris)

Véronique Vodovar (INSERM U953, Paris)

Project Coordination and Data Analysis Committee: François Goffinet, Babak Khoshnood, Nathalie Lelong, Anne-Claire Thieulin, Thibaut Andrieu, Véronique Vodovar

Independent Data Monitoring Committee (URC Paris Centre et CIC Cochin Necker Mère Enfant): Maggy Chausson, Anissa Brinis, Laure Faure, Maryline Delattre, Jean-Marc Treluyer (Groupe Hospitalier Cochin-Hôtel Dieu, AP-HP, Université Paris Descartes, Paris)

External Scientific Committee: Gérard Bréart, Dominique Cabrol, Alain Sérraf, Daniel Sidi, Marcel Voyer

Participating Centers: The Greater Paris Area (Paris and its surrounding suburbs) public (AP-HP) and private maternity units, Departments of Pediatric Cardiology and Pediatric Cardiac Surgery, pediatric cardiologists in private practice, Neonatal Intensive Care Units, Pediatric Intensive Care Units, Emergency Transfer Services (SMUR), Departments of Pathology, Sudden Death Centers, Departments of Family and Infant Protection (DFPE)

\section{Author details}

'Inserm, UMR S953, Epidemiological research on perinatal health, mothers and children health, Port-Royal Maternity, Gème étage 53 avenue de I'Observatoire, Paris 75014, France. ${ }^{2}$ Congenital heart defects surgery unit, Marie Lannelongue Hospital, Le Plessis Robinson 92350, France. ${ }^{3}$ Complex congenital heart defects reference center - M3C-Necker, Paris Descartes University, Sorbonne Paris Cité, Paris 75015, France. ${ }^{4}$ Port Royal Maternity - Cochin Hospital, Assistance Publique Hôpitaux de Paris, Paris Descartes University, Sorbonne Paris Cité, Paris 75014, France.

Received: 17 September 2013 Accepted: 3 January 2014

Published: 20 February 2014

\section{References}

1. Blondel B, Kaminski M: Trends in the occurrence, determinants, and consequences of multiple births. Semin Perinatol 2002, 26(4):239-249.

2. Nyboe Andersen A, Goossens V, Bhattacharya S, Ferraretti AP, Kupka MS, de Mouzon J, Nygren KG: Assisted reproductive technology and intrauterine inseminations in Europe, 2005: results generated from European registers by ESHRE: ESHRE. The European IVF monitoring programme (EIM), for the European Society of Human Reproduction and Embryology (ESHRE). Hum Reprod 2009, 24(6):1267-1287.

3. Bower C, Hansen M: Assisted reproductive technologies and birth outcomes: overview of recent systematic reviews. Reprod Fertil Dev 2005, 17(3):329-333.

4. Buckett WM, Tan SL: Congenital abnormalities in children born after assisted reproductive techniques: how much is associated with the presence of infertility and how much with its treatment? Fertil Steril 2005, 84(5):1318-1319. discussion 1327

5. Hansen M, Bower C, Milne E, de Klerk N, Kurinczuk JJ: Assisted reproductive technologies and the risk of birth defects-a systematic review. Hum Reprod 2005, 20(2):328-338.

6. Hansen M, Kurinczuk JJ, Bower C, Webb S: The risk of major birth defects after intracytoplasmic sperm injection and in vitro fertilization. $N$ Engl $J$ Med 2002, 346(10):725-730

7. Klemetti R, Gissler M, Sevon T, Koivurova S, Ritvanen A, Hemminki E: Children born after assisted fertilization have an increased rate of major congenital anomalies. Fertil Steril 2005, 84(5):1300-1307. 
8. Koivurova S, Hartikainen AL, Gissler M, Hemminki E, Sovio U, Jarvelin MR: Neonatal outcome and congenital malformations in children born after in-vitro fertilization. Hum Reprod 2002, 17(5):1391-1398.

9. Olson CK, Keppler-Noreuil KM, Romitti PA, Budelier WT, Ryan G, Sparks AE, Van Voorhis BJ: In vitro fertilization is associated with an increase in major birth defects. Fertil Steril 2005, 84(5):1308-1315.

10. Schieve LA, Rasmussen SA, Reefhuis J: Risk of birth defects among children conceived with assisted reproductive technology: providing an epidemiologic context to the data. Fertil Steril 2005, 84(5):1320-1324. discussion 1327.

11. Davies MJ, Moore VM, Willson KJ, Van Essen P, Priest K, Scott H, Haan EA, Chan A: Reproductive technologies and the risk of birth defects. N Engl J Med 2012, 366(19):1803-1813.

12. Reefhuis J, Honein MA, Schieve LA, Correa A, Hobbs CA, Rasmussen SA: Assisted reproductive technology and major structural birth defects in the United States. Hum Reprod 2009, 24(2):360-366.

13. Reefhuis J, Honein MA, Schieve LA, Rasmussen SA: Use of clomiphene citrate and birth defects, National Birth Defects Prevention Study, 1997-2005. Hum Reprod 2011, 26(2):451-457.

14. Tararbit K, Houyel L, Bonnet D, De Vigan C, Lelong N, Goffinet F, Khoshnood B: Risk of congenital heart defects associated with assisted reproductive technologies: a population-based evaluation. Eur Heart J 2011, 32(4):500-508.

15. Tararbit K, Lelong N, Thieulin AC, Houyel L, Bonnet D, Goffinet F, Khoshnood B: The risk for four specific congenital heart defects associated with assisted reproductive techniques: a population-based evaluation. Hum Reprod 2013, 28(2):367-374.

16. Glinianaia SV, Rankin J, Wright C: Congenital anomalies in twins: a register-based study. Hum Reprod 2008, 23(6):1306-1311.

17. Weber MA, Sebire NJ: Genetics and developmental pathology of twinning. Semin Fetal Neonatal Med 2010, 15(6):313-318.

18. Bahtiyar MO, Dulay AT, Weeks BP, Friedman AH, Copel JA: Prevalence of congenital heart defects in monochorionic/diamniotic twin gestations: a systematic literature review. J Ultrasound Med 2007, 26(11):1491-1498.

19. Campbell KH, Cope JA, Ozan Bahtiyar M: Congenital heart defects in twin gestations. Minerva Ginecol 2009, 61(3):239-244.

20. Manning $\mathrm{N}$ : The influence of twinning on cardiac development. Early Hum Dev 2008, 84(3):173-179.

21. Hajdu J, Beke A, Marton T, Hruby E, Pete B, Papp Z: Congenital heart diseases in twin pregnancies. Fetal Diagn Ther 2006, 21(2):198-203.

22. Cocchi G, Gualdi S, Bower C, Halliday J, Jonsson B, Myrelid A, Mastroiacovo P, Amar E, Bakker MK, Correa A, Doray B, Melve KK, Koshnood B, Landau D, Mutchinick OM, Pierini A, Ritvanen A, Ruddock V, Scarano G, Sibbald B, Sipek A, Tenconi R, Tucker D, Anneren G: International trends of down syndrome 1993-2004: births in relation to maternal age and terminations of pregnancies. Birth Defects Res A Clin Mol Teratol 2010, 88(6):474-479.

23. Eurocat: Special report: congenital heart defects in Europe, 2000-2005. ; 2009. Available at: http://www.eurocat-network.eu/content/Special-Report-CHD.pdf.

24. Greenlees R, Neville A, Addor MC, Amar E, Arriola L, Bakker M, Barisic I, Boyd PA, Calzolari E, Doray B, Draper E, Vollset SE, Garne E, Gatt M, Haeusler M, Kallen K, Khoshnood B, Latos-Bielenska A, Martinez-Frias ML, Materna-Kiryluk A, Dias CM, McDonnell B, Mullaney C, Nelen V, O'Mahony M, Pierini A, Queisser-Luft A, Randrianaivo-Ranjatoelina H, Rankin J, Rissmann A, et al: Paper 6: EUROCAT member registries: organization and activities. Birth Defects Res A Clin Mol Teratol 2011, 91(Suppl 1):S51-S100.

25. Khoshnood B, Greenlees R, Loane M, Dolk H: Paper 2: EUROCAT public health indicators for congenital anomalies in Europe. Birth Defects Res A Clin Mol Teratol 2011, 91(Suppl 1):S16-S22.

26. Khoshnood B, Lelong N, Houyel L, Thieulin AC, Jouannic JM, Magnier S, Delezoide AL, Magny JF, Rambaud C, Bonnet D, Goffinet F: Prevalence, timing of diagnosis and mortality of newborns with congenital heart defects: a population-based study. Heart 2012, 98(22):1667-1673.

27. Hook EB: Normal or affected controls in case-control studies of congenital malformations and other birth defects: reporting bias issues. Epidemiology 1993, 4(2):182-184.

28. Smith LK, Budd JL, Field DJ, Draper ES: Socioeconomic inequalities in outcome of pregnancy and neonatal mortality associated with congenital anomalies: population based study. BMJ 2011, 343:d4306

29. Vrijheid M, Dolk H, Stone D, Abramsky L, Alberman E, Scott JE: Socioeconomic inequalities in risk of congenital anomaly. Arch Dis Child 2000, 82(5):349-352.

30. Buis ML: Direct and indirect effects in a logit model. Stata J 2010, 10(1):11-29.
31. Erikson R, Goldthorpe $J H$, Jackson M, Yaish M, Cox DR: On class differentials in educational attainment. Proc Natl Acad Sci U S A 2005, 102(27):9730-9733.

32. Kuwata T, Matsubara S, Ohkuchi A, Watanabe T, Izumi A, Honma Y, Yada Y, Shibahara $H$, Suzuki M: The risk of birth defects in dichorionic twins conceived by assisted reproductive technology. Twin Res 2004, 7(3):223-227.

33. Apitz C, Webb GD, Redington AN: Tetralogy of Fallot. Lancet 2009, 374(9699):1462-1471

34. Di Felice V, Zummo G: Tetralogy of fallot as a model to study cardiac progenitor cell migration and differentiation during heart development. Trends Cardiovasc Med 2009, 19(4):130-135.

35. Bittel DC, Butler MG, Kibiryeva N, Marshall JA, Chen J, Lofland GK, O'Brien JE $\mathrm{Jr}$ : Gene expression in cardiac tissues from infants with idiopathic conotruncal defects. BMC Med Genomics 2011, 4:1

36. Bruneau BG: The developmental genetics of congenital heart disease. Nature 2008, 451(7181):943-948.

37. O'Brien JE Jr, Kibiryeva N, Zhou XG, Marshall JA, Lofland GK, Artman M, Chen J, Bittel DC: Noncoding RNA expression in myocardium from infants with tetralogy of Fallot. Circ Cardiovasc Genet 2012, 5(3):279-286.

38. van Weerd JH, Koshiba-Takeuchi K, Kwon C, Takeuchi JK: Epigenetic factors and cardiac development. Cardiovasc Res 2011, 91(2):203-211.

39. Hutson MR, Kirby ML: Model systems for the study of heart development and disease. Cardiac neural crest and conotruncal malformations. Semin Cell Dev Biol 2007, 18(1):101-110.

40. Jauniaux E, Ben-Ami I, Maymon R: Do assisted-reproduction twin pregnancies require additional antenatal care? Reprod Biomed Online 2013, 26(2):107-119

41. Pinborg A, Wennerholm UB, Romundstad LB, Loft A, Aittomaki K, Soderstrom-Anttila V, Nygren KG, Hazekamp J, Bergh C: Why do singletons conceived after assisted reproduction technology have adverse perinatal outcome? Systematic review and meta-analysis. Hum Reprod Update 2013, 19(2):87-104.

42. Sazonova A, Kallen K, Thurin-Kjellberg A, Wennerholm UB, Bergh C: Factors affecting obstetric outcome of singletons born after IVF. Hum Reprod 2011, 26(10):2878-2886.

43. van Oppenraaij RH, Jauniaux E, Christiansen OB, Horcajadas JA, Farquharson $R G$, Exalto N: Predicting adverse obstetric outcome after early pregnancy events and complications: a review. Hum Reprod Update 2009, 15(4):409-421.

44. Botto LD, Mulinare J, Erickson JD: Occurrence of congenital heart defects in relation to maternal mulitivitamin use. Am J Epidemiol 2000, 151(9):878-884

45. Blondel B, Lelong N, Kermarrec M, Goffinet F: Trends in perinatal health in France from 1995 to 2010. Results from the French National Perinatal Surveys. J Gynecol Obstet Biol Reprod (Paris) 2012, 41(4):e1-e15.

46. Zhu JL, Basso O, Obel C, Bille C, Olsen J: Infertility, infertility treatment, and congenital malformations: Danish national birth cohort. BMJ 2006 333(7570):679.

doi:10.1186/1750-1172-9-27

Cite this article as: Tararbit et al:: Assessing the role of multiple pregnancies in the association between tetralogy of Fallot and assisted reproductive techniques: a path-analysis approach. Orphanet Journal of Rare Diseases 2014 9:27

\section{Submit your next manuscript to BioMed Central and take full advantage of:}

- Convenient online submission

- Thorough peer review

- No space constraints or color figure charges

- Immediate publication on acceptance

- Inclusion in PubMed, CAS, Scopus and Google Scholar

- Research which is freely available for redistribution 